\title{
Redirecting a Scattered Public Toward Alternative Matters of Concern: Shifting Perceptions of Urban Wastewater Governance in Indonesia Tanja Rosenqvist
}

\footnotetext{
See, e.g., Alastair Fuad-Luke, Design Activism: Beautiful Strangeness for a Sustainable World (London: Earthscan, 2009); Anthony Dunne and Fiona Raby, Speculative Everything: Design, Fiction, and Social Dreaming (Cambridge, MA: MIT Press, 2013); Carl DiSalvo, Adversarial Design (Cambridge, MA: MIT Press, 2012); and Ezio Manzini and Rachel Coad, Design, When Everybody Designs: An Introduction to Design for Social Innovation (Cambridge, MA: MIT Press, 2015).

2 Latour makes the distinction between matters of fact and matters of concern. Bruno Latour, "Why Has Critique Run out of Steam? From Matters of Fact to Matters of Concern," Critical Inquiry 30, no. 2 (2004): 225-48.

3 See e.g., Carl Disalvo, Jonathan Lukens, Thomas Lodato, Tom Jenkins, and Tanyoung Kim, "Making Public Things: How HCI Design Can Express Matters of Concern," CHI '14 Proceedings of the SIGCHI Conference on Human Factors in Computing Systems (New York: ACM, 2014), 2397-406; Kristina Lindström and Åsa Ståhl, “Becoming Response-Able Stakeholders: Participatory Design in Times of Uncertainties," PDC '16 Proceedings of the 14th Participatory Design Conference 2 (New York: ACM, 2016): 41-44; Carl DiSalvo, "Critical Making as Materializing the Politics of Design," Information Society 30, no. 2 (2014): 96-105; and Christopher Le Dantec, Designing Publics (Cambridge, MA: MIT Press, 2016).
}

\section{Introduction}

Societies around the world today are facing increasingly complex societal challenges and the role of the nation state vis-a-vis citizens-even the very notion of democracy itself-is, at the same time, changing and being challenged. In the field of design, these challenges have led to a growing interest in the disruptive potential of design. Emerging and re-emerging fields of design, such as social design, design activism, critical design, and adversarial design, each in their own way prompt designers to explore, highlight, or even solve contemporary societal challenges through disruptive designerly interventions. ${ }^{1}$

The making or design of publics is one way the disruptive potential of design is currently being explored. The (often temporary) publics resulting from design interventions gather people and materials around shared concerns-around what, in the words of Latour, might be called "matters of concern." ${ }^{2}$ For example, designers have gathered publics around concerns of air pollution, plastic consumption, agriculture, and homelessness. ${ }^{3}$

This paper builds on previous research into the making of publics and explores the role of design not in making, but in redirecting existing and often scattered publics toward alternative matters of concern. With this paper, I specifically share my experience, as a designer, in the action research project, "Governing Futures - Voices and Wastewater," in which I used designerly means to engage members of low-income urban communities in Indonesia in critically examining and questioning their existing matters of concern and to redirect them toward alternative concerns related to urban wastewater governance. 
The paper has five parts. First, I address the difference between "making" and "redirecting" publics; second, I introduce the issue of urban wastewater governance in Indonesia; third, I describe how, through designerly means, I redirected an existing public toward alternative matters of concern; fourth, I offer some important reflections on the role of designers in such endeavors. The paper ends with a conclusion.

4 In relation to the former, see e.g., Carl DiSalvo, "Design and the Construction of Publics," Design Issues 25, no. 1 (Winter 2009): 48-63; for the latter, see, e.g., Christopher A. Le Dantec, Designing Publics (Cambridge, MA: MIT Press, 2016); C. L. Dantec and Carl DiSalvo, "Infrastructuring and the Formation of Publics in Participatory Design," Social Studies of Science 43, no. 2 (2013): 241-64; and Per-Anders Hillgren, Anna Seravalli, and Anders Emilson, "Prototyping and Infrastructuring in Design for Social Innovation," CoDesign 7, no. 3-4 (2011): 169-83.

5 John Dewey, The Public and Its Problems (Athens, OH: Swallow Press, 1988): 33-35.

6 Noortje Marres, "Issues Spark a Public into Being: A Key But Often Forgotten Point of the Lippmann-Dewey Debate," in Making Things Public: Atmospheres of Democracy, ed. Bruno Latour and Peter Weibel (Cambrige, MA: The MIT Press, 2014), 208-17.

7 Ibid., 208.

8 DiSalvo, "Design and the Construction of Publics," 52-58.

9 The notion of design as infrastructuring is explored in Erling Björgvinsson, Pelle Ehn, and Per-Anders Hillgren, "Agonistic Participatory Design: Working with Marginalized Social Movements," CoDesign 8, no. 2-3 (2012): 127-44; and Pelle Ehn, "Participation in Design Things," PDC '08 Proceedings of theTenth Anniversary Conference on Participatory Design 2008 (Bloomington, IN: Indiana University, 2008), 92-101. The notion of democratic design experiments is explored in Thomas Binder, Eva Brandt, Pelle Ehn, and Joachim Halse, "Democratic Design Experiments: Between Parliament and Laboratory," CoDesign 11, no. 3-4, (October 2015): 152-65, https://doi.org/10.1080/15710882.2015 1081248.

10 Ibid., 162

\section{From Making to Redirecting the Deweyan Public}

Research into the relationship between design and publics has so far focused mainly on the role of design in making publics. Drawing on John Dewey's seminal book, The Public and Its Problems, and on the exhibition and book, Making Things Public: Atmospheres of Democracy, curated and edited by Latour and Weibel, design researchers have explored design for two purposes: as a way of making issues known so as to "spark" a public into being and as a way of developing long-term relationships among stakeholders (infrastructuring) so as to motivate a public to gather. ${ }^{4}$

The use of design to "spark" publics into being builds on Dewey's notion that a public is called into being by negative externalities. ${ }^{5}$ Citizens who experience the externalities might form a public around a shared concern and an interest in alleviating the issue-or in the words of Marres, "issues spark a public into being." ${ }^{\prime \prime}$ Especially complex issues-issues that existing institutions have been unable to deal with-seem to enable and even encourage public involvement in politics. ${ }^{7}$ Building on this idea, designers have explored how design can make complex issues public. For example, DiSalvo has suggested two design strategies: projection and tracing. ${ }^{8} \mathrm{He}$ describes projection as the representation of possible future consequences associated with an issue, and he describes tracing as a way of making known the network of materials, concepts, and values that shape and frame an issue.

Making an issue known is not enough to bring the Deweyan public into being, however. The Deweyan public is a bold vision of a deliberate democracy that, according to Dewey, calls for collaborative problem-solving and strong social ties. Design literature that explores the making of publics, especially within the tradition of participatory design, has therefore also explored the use of design as "infrastructuring." This notion refers to design as a means of building long-term relationships among divers actors. Binder et al. similarly talk about democratic design experiments, which they describe as design interventions through which issues and publics are formed simultaneously. ${ }^{9}$ According to Binder et al., such infrastructuring practices might involve applying a distinct designerly mode of agency: the creation of proposals that prompt participation in publics..$^{10}$ 
11 Dewey, The Public and Its Problems, 146.

12 Badan Perencanaan Pembangunan Nasional [National Development Planning Agency] (BAPPENAS) and Water and Sanitation Program (WSP),"It's Not a Private Matter Anymore!" (Jakarta, Indonesia: BAPPENAS, Government of Indonesia with WSP, 2007), https://esa. un.org/iys/docs/san_lib_docs/Not a Private Matter Anymore.pdf (accessed on May 15, 2015).

13 Sinarko Wibowo and Handy Legowo, "SANIMAS Approach and ISSDP City-Wide Sanitation Strategy (CSS)," Water Practice \& Technology 5, no. 4 (2010): 1-20; Kathy Eales, Reini Siregard, Evi Febriani, Isabel Blackett, "Review of Community Managed Decentralized Wastewater Treatment Systems in Indonesia" (Washington, DC: World Bank Water and Sanitation Program, 2013).

14 World Bank and Australian Agency for International Development (AusAID), "Indonesia: Country Study - East Asia Pacific Region Urban Sanitation Review" (Washington, DC: World Bank, 2013), https://openknowledge.worldbank.org/ handle/10986/17614, (accessed on December 16, 2017)

15 Freya Mills, Juliett Willetts, and Mohamad Mova Al'Afghani, "Increasing Local Government Responsibility for Community Scale Sanitation. Part 1: Review of National Program Guidelines and Two City Case Studies," 2017; Cynthia Mitchell et al., "Governance of Local Scale Sanitation: Visual Synthesis Report for Key Stakeholders in Indonesia," (Sydney, Australia: Institute for Sustainable Futures, University of Technology Sydney, 2016), https://opus. lib.uts.edu.au/handle/10453/88133 (accessed on December 16, 2017). Note that the average cost of implementing a system ranges from US $\$ 38,000-\$ 42,000$ (IDR 525-575 million). This amount covers materials and implementation costs but does not include salaries of local and national government staff or the cost of communities' volunteer labor or in-cash contributions.
Building on the previous research into the role of design in "making" publics, I explore yet another important aspect of the Deweyan public: that it might already exist but remains "largely scattered, mobile and manifold." ${ }^{\prime 11}$ Designers engaged in making publics do not enter a world not yet inhabited; they enter a world of scattered publics and existing matters of concern. As the literature has shown, designers can explore such concerns and develop designerly ways of "sparking" publics into being and "infrastructuring" publics. However, what if, from the designer's perspective, gathering around existing matters of concern is not in the best interest of the public itself or the common good? What if she or he believes an existing matter of concern represents just one perspective on a far more complex societal issue? What if alternative matters of concern are worth gathering around? What is the role of the designer then? To explore these questions, I consider the issue of wastewater governance in Indonesia and describe how I used design as a means of redirecting an existing but largely scattered public toward alternative matters of concern.

\section{Wastewater as a (Public) Matter of Concern}

In Indonesia, the world's fourth most populous country, wastewater historically has been considered a private matter. ${ }^{12}$ Public investment in sanitation infrastructure and sanitation service provision has therefore been minimal, and only 2 percent of Indonesia's 250 million people today have access to centralized sewage services..$^{13}$

Wastewater is increasingly becoming a public matter of concern in Indonesia, and new sanitation strategies (e.g., decentralized sanitation) are emerging. More specifically, government investments in sanitation have increased eightfold from 2006 to 2012. ${ }^{14}$ In addition, since 2004 more than 20,000 decentralized sanitation systems have been funded for implementation. The Government of Indonesia (GoI) further plans to provide 7.5 percent of the population with access to decentralized sanitation by 2019, resulting in a total of 100,000 systems and a further investment of at least US $\$ 3$ billion. ${ }^{15}$

While GoI and international donors fund the implementation of decentralized sanitation systems, the low-income communities in which they are implemented are expected to take full responsibility for ongoing operation and maintenance, as well as user fee collection. Upon inauguration, responsibility is handed to a so-called community-based organization (CBO), which typically consists of three to four community members who operate and maintain the system voluntarily. 

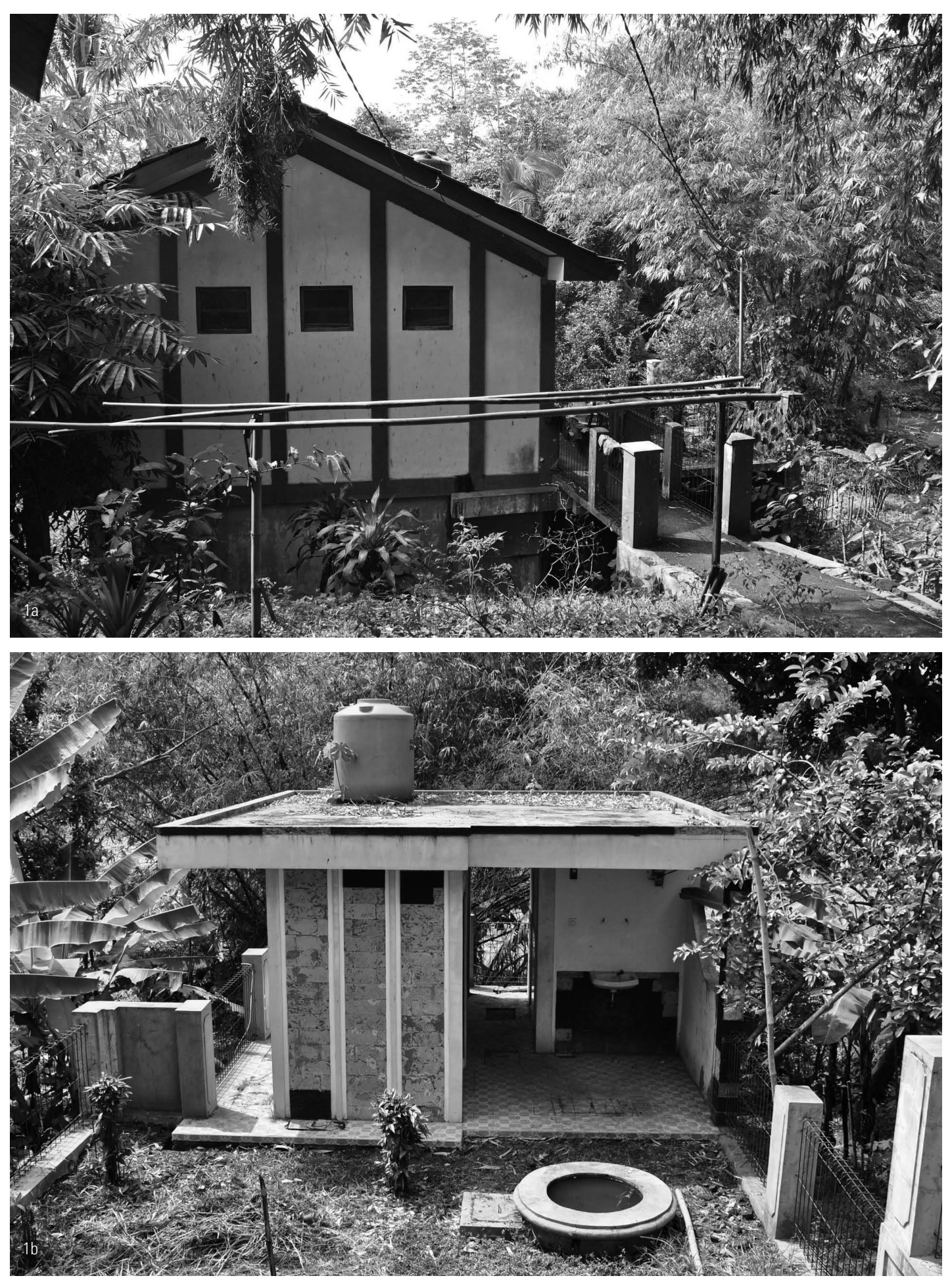

Figures $1 \mathrm{a}$ and $1 \mathrm{~b}$

Decentralized sanitation systems in two Bogor communities. Photos by Tanja Rosenqvist. 
The long-term sustainability of decentralized sanitation services under this current community management model is increasingly being questioned. A recent World Bank report found that many CBOs do not collect enough user fees or sufficiently maintain their systems. ${ }^{16}$ The study therefore concluded that "the assumption that communities can and will manage facilities and wastewater treatment on their own without external support is overstated." ${ }^{17}$ Furthermore, the study's authors suggested moving away from the current community management model and toward co-management, so that communities and local governments share responsibility for ongoing operation and maintenance.

The Governing Futures-Voices and Wastewater project started from the belief that changes to the governance of decentralized sanitation were needed. The purpose of the project was therefore to explore whether and how a public might be gathered around a shared concern to advocate for change.

\section{Redirecting a Scattered Public Toward Alternative Matters of Concern}

Governing Futures-Voices and Wastewater was conducted in a densely populated city of one million inhabitants located on the main island of Java. Since 2007, 96 communities within the case study city have implemented decentralized systems. (Examples are shown in Figures 1a and 1b.)

The research started with an exploration of existing matters of concern through interviews with members of three urban communities and local government staff. Interviewees confirmed the unsustainability of decentralized sanitation services and suggested that both the operation and maintenance and the user fee collection had to be improved. CBO members in all three communities specifically agreed that the problem was a lack of what they called "community awareness." They suggested that communities (including each of the ones they represented) should take more initiative and be more aware of the need to operate and maintain the systems. Local government staff and representatives from local non-governmental organizations (NGOs) agreed. They argued that increasing "community awareness" through socialisasi-educational efforts conducted by government and NGOs-was necessary to "change the mindset" of community members. A scattered public therefore seemed to already exist and to have community awareness as a shared matter of concern.

Interestingly, interviews with community members fur-

16 This study looked at the condition of decentralized sanitation services in almost 400 communities in Indonesia. Eales et al., "Review of Community Managed Decentralized Wastewater Treatment Systems in Indonesia": 5.

17 Ibid., 162 ther revealed that $\mathrm{CBO}$ leaders also were concerned about the burden of managing decentralized sanitation systems. For example, 
18 See e.g., John Bowen, "On the Political Construction of Tradition: Gotong Royong in Indonesia," Journal of Asian Studies 45, no. 3 (1986): 545-61; John Sullivan, "Inventing and Imagining Community: Two Modern Indonesian Ideologies" (Working Papers, Monash University, Monash Asia Institute), no. 69 (1995): $1-27$.

19 Bowen, "On the Political Construction of Tradition"; Sullivan, "Inventing and Imagining Community"; Diaswati Mardiasmo and Paul Barnes, "Community Response to Disasters in Indonesia: Gotong Royong, a Double-Edged Sword," Proceedings of the 9th Annual International Conference of the International Institute for Infrastructure Renewal and Reconstruction, Queensland University of Technology, Brisbane, Australia, (2013): 301-07.

20 Vijayendra Rao, "Symbolic Public Goods and the Coordination of Collective Action: A Comparison of Local Development in India and Indonesia," in The Contested Commons: Conversations Between Economists and Anthropologists, ed. Pranah Bardhan and Isha Ray (0xford: Blackwell Publishing, 2008), 1-26, (15).
CBO leaders were frustrated by the lack of support they received both from community members and from local government, and they described how they felt as though they were left alone with the responsibility. One of the CBO leaders further explained how government projects, including decentralized sanitation, had become a burden:

From my point of view, with my previous experience, the project from government is important for us, especially for us as representatives from the community, because if there is something wrong, [the] community will blame us. But I think [the] government program is a burden for me.

When asked whether his community would say yes to building a decentralized sanitation system if they were asked today, he promptly answered, "No we don't want it. If I were the one who decided in 2010, I would definitely say no. We would reject this project."

This response seemed curious; although members of the scattered public shared a concern for the lack of "community awareness," CBO leaders also showed concern for the burden of managing decentralized sanitation system. The question therefore was why CBO members' main matter of concern was their own lack of awareness, rather than for example the lack of ongoing support from local government.

Further research revealed that CBO members' existing matters of concern might be influenced by the largely engrained cultural concept of gotong royong: mutual and reciprocal assistance. ${ }^{18}$ Gotong royong was traditionally a form of voluntary labor performed by rural communities in Indonesia, motivated by a concern for the common good. However, more recently, gotong royong has been described as a state construct and a form of obligatory labor demanded by the state. ${ }^{19}$ As Rao suggests, "...the spirit of gotong royong has... been so deeply institutionalized that not abiding by it is sensed by people as a violation of a communitarian ethic..." ${ }^{20}$

Based on the research findings, I decided that rather than gathering a public, I would use design to question the scattered publics' existing matter of concern and to redirect the public toward an alternative matter of concern. I had witnessed how decentralized systems - when not maintained-can pose a significant risk to public and environmental health and how $\mathrm{CBO}$ members might experience decentralized sanitation as a burden. I had furthermore seen that community-management draws on the concept of gotong royong (mutual collaboration), a form of obligatory labor demanded by the state. Questioning whether the lack of "community awareness" should be the main matter of concern, therefore, seemed to be in the interest of CBOs and the public more generally. 


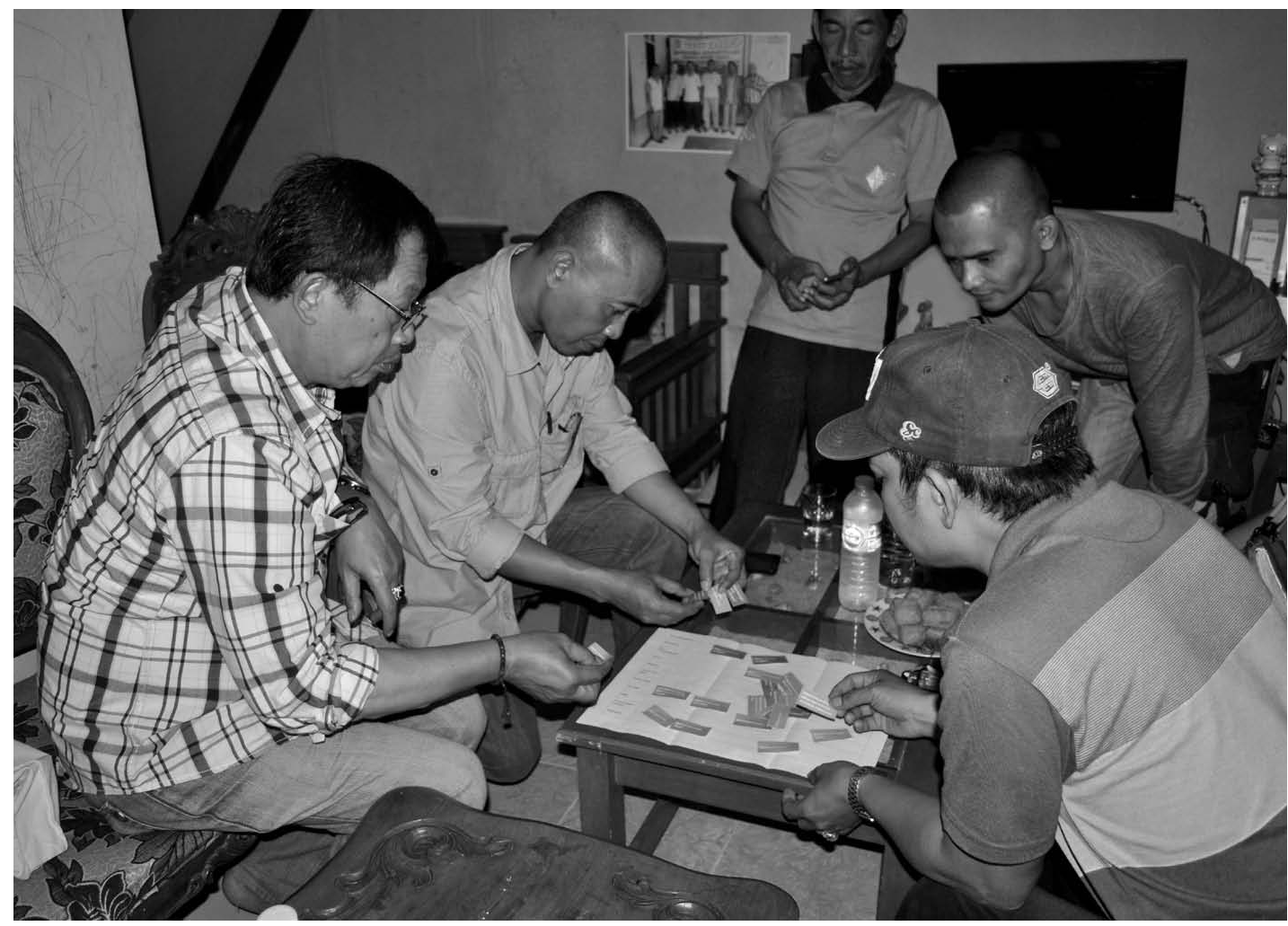

Figures 2

CBO members mapping responsibilities in the Responsibility Game. Photo by Tanja Rosenqvist.
21 For the use of design games in participatory design, see e.g., Eva Brandt, “Designing Exploratory Design Games: A Framework for Participation in Participatory Design?" in Proceedings of the Ninth Conference on Participatory Design: Expanding Boundaries in Design, Volume 1, (Trento: Italy, ACM: 2006), 57-66; Eva Brandt and Jörn Messeter, "Facilitating Collaboration Through Design Games," in Proceedings of the Eighth Conference on Participatory Design: Artful Integration: Interweaving Media, Materials and Practices 1 (Toronto, Canada: ACM, 2004): 121-31.

\section{Questioning Existing Matters of Concern}

To question the scattered public's existing matter of concern, a game inspired by the design games often used in the tradition of participatory design was developed. ${ }^{21}$ The Responsibility Game consisted of a game board and a set of game pieces. The board, a piece of A3 paper, had 11 rows, each representing a sanitation stakeholder (e.g., CBO, community leader, local government infrastructure implementation department, and water utility). Each game piece represented a responsibility related to the ongoing operation and maintenance of decentralized systems, such as collecting user fees, cleaning grease traps, desludging, and bookkeeping. During interviews in communities, $\mathrm{CBO}$ members were asked to decide collaboratively where to place each responsibility piece to indicate the stakeholder who they believed today has that responsibility. (See Figure 2.) The conversations were recorded and later transcribed, and the final mappings were photographed. Furthermore, transcripts and photographs from all three communities were compared to draw out similarities in participants' reactions to the game and their final mappings.

All three CBOs placed the majority of the responsibilities across the two rows representing the community leader and the CBO. Two CBOs also placed responsibilities with local government departments and NGOs, while the CBO leader in the third community, with body language signaling clear displeasure, placed half of the responsibilities across community stakeholders and 

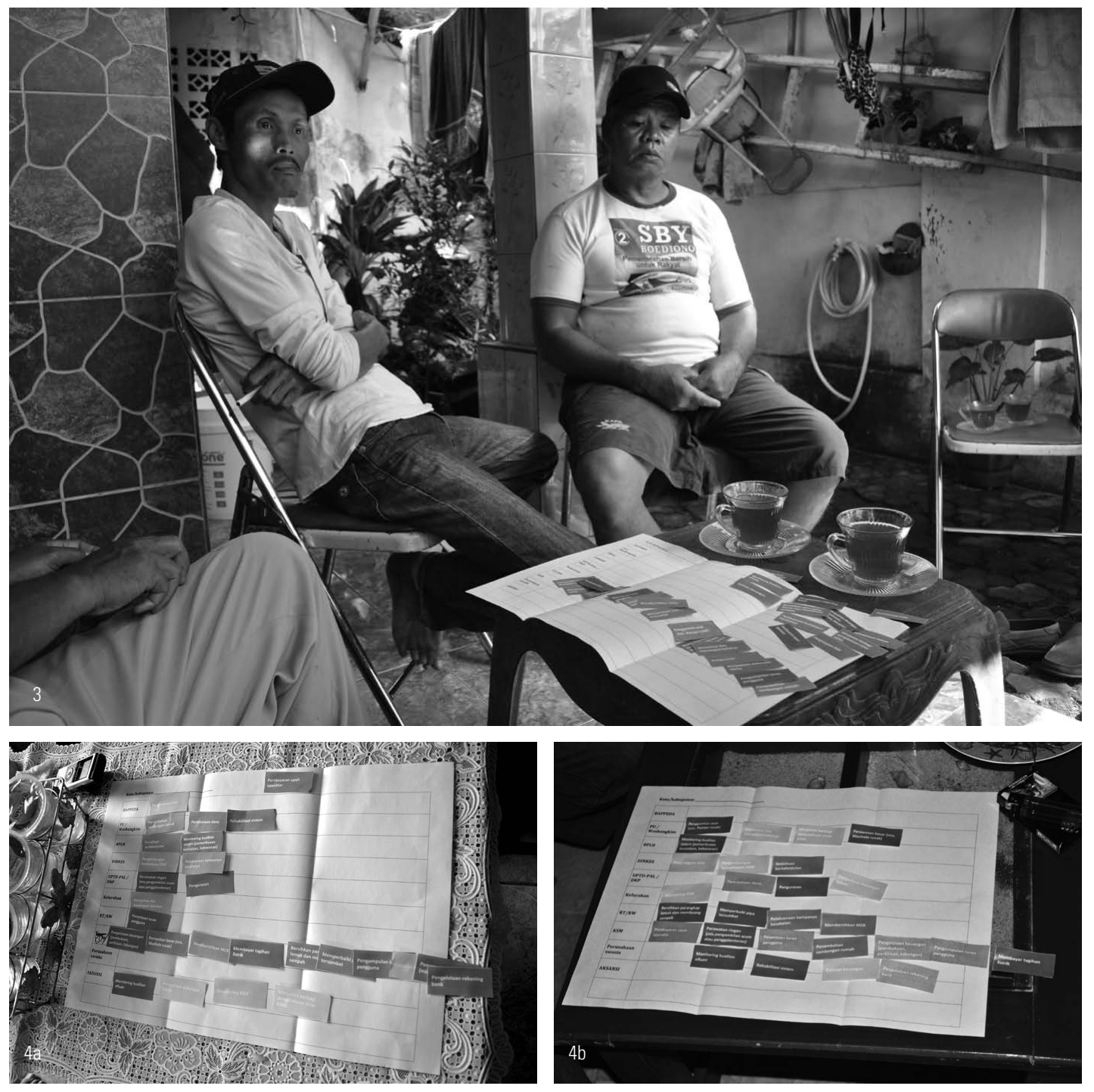

Figure 3

$\mathrm{CBO}$ members and the finished Responsibility Game. Photo by Tanja Rosenqvist.

Figures $4 a$ and $4 b$

Two examples of finished mappings, with the majority of responsibilities assigned to community stakeholders. Photos by Tanja Rosenqvist. pushed the remaining pieces to the corner of the game board, visibly suggesting that no one was taking care of them. (See Figure 3.)

The mappings became visual manifestations of the challenges faced by CBOs. All three mappings suggested that the responsibilities today given to communities extend beyond the boundaries of the game board and thus visually extended beyond the capacity of the community. (See Figures $4 a$ and $4 b$.)

$\mathrm{CBO}$ members reacted to the mappings with a mix of surprise and a need to justify. For example, one $\mathrm{CBO}$ leader pondered, "[w] hy so many responsibilities on the CBO? The one that is most responsible is the CBO." Shortly after, he explained, "[i]n the beginning it looks like a lot of work, but if everything works, it is not so bad." However, the reality is that everything might not "work." For example, in his community at the time of the interview, user fees had not been collected for more than a year. 
To further question CBO members' existing matters of concern, I asked for permission to suggest an alternative to the mappings developed by participants. I then moved the majority of the responsibilities, which $\mathrm{CBO}$ members had placed with the community, to the rows symbolizing the water utility and the local government implementation department. In design terms, I provided what Binder et al. call a "proposal to prompt participation" - but an activist one. ${ }^{22}$ The "activist" proposal was both reasonable and feasible (and in line with service models found, for example, in Malaysia, the United States, and Japan). ${ }^{23}$ It questioned the level of responsibility currently handed to communities and, furthermore, suggested that communities did not have to take on all these responsibilities; they could be shared with local government and the water utility

My activist proposal both challenged and intrigued $\mathrm{CBO}$ members. One CBO leader explained that he was worried about the potential increase in user fees, while another worried about the feasibility of the approach and suggested that the community should keep more responsibilities. In the third CBO leader, after a bit of contemplation said: "So, I think this is good, because what I mentioned earlier, when our burden was $100 \mathrm{~kg}$, it is now reduced to $40 \mathrm{~kg}$." In other words, my proposal was met with a mix of confusion, reluctance, and hope.

Although the proposal intrigued $\mathrm{CBO}$ members, they were not immediately willing to join a public gathering around a new matter of concern. This hesitation became evident when I invited $\mathrm{CBO}$ members to join a co-design workshop to share their experiences of decentralized sanitation with other CBOs, local governments, and NGO stakeholders and to discuss opportunities for moving towards co-management. The $\mathrm{CBO}$ members were reluctant to participate in the workshop. One $\mathrm{CBO}$ leader in particular was clearly uncomfortable with the idea:

I don't know if I can make it on Tuesday. What I am worried about is that if we mention this, the government will say 'we already give you the facility and it is your fault if you cannot maintain it.' I am not sure I can make it because I don't feel comfortable, [and] because our location is probably different [from] other locations where they have [CBO] structure."

The $\mathrm{CBO}$ leader seemed afraid of sharing his (negative) experiences with local government stakeholders and to openly admit that his community was struggling to maintain the decentralized system. Although he agreed that local governments could be more involved in operation and maintenance, fear prohibited him from joining a public advocating for such a change, and on the day of the workshop, he and the rest of his CBO did not show up. 
The CBO leaders' reactions suggested that redirecting a scattered public toward an alternative matter of concern might involve more than "sparking" a public into being around an alternative matter of concern. In this case, redirecting also would involve overcoming societal norms and values associated with gotong royong, as well as $\mathrm{CBO}$ members' fears of sharing (negative) experiences with local government stakeholders.

\section{Proposing Alternative Matters of Concern}

The co-design workshop, held the following week, brought together CBO members, local government, and NGO stakeholders to discuss opportunities for moving toward a co-management model-toward communities and local governments sharing postconstruction responsibilities.

The workshop started with a few presentations quantifying the unsustainability of decentralized sanitation service provision in Indonesia more broadly, and in the case study city specifically. The presentations highlighted that at least 30 percent of communities with decentralized sanitation systems are not collecting sufficient user fees and that 80 percent of communities are not desludging their systems regularly. ${ }^{24}$ Based on data from the case study city, 32 of 41 systems monitored in 2015 experienced problems. The purpose of the presentations was to normalize the (negative) experiences of $\mathrm{CBO}$ members by showing them, as well as local government stakeholders, that many communities are challenged. In other words, the purpose was to "spark" a public into being around the burden of community management and a need for further support from local government.

After the presentations, the participants were divided into three groups, each comprising $\mathrm{CBO}$ members, local government representatives, and NGO representatives. The participants in these groups were first asked to map the current division of responsibilities by using the Responsibility Game and afterward to imagine and map what a co-management model might look like in practice. The groups were particularly urged to move three specific responsibilities away from communities: user fee collection, desludging, and system rehabilitation. Research had suggested that these responsibilities seemed particularly neglected or challenging for communities. ${ }^{25}$

Some opposition to developing a co-management model had been expected, but the reaction was surprising-especially from local government and NGO representatives. The groups agreed to move desludging and system rehabilitation to government stakeholders, but they were not willing to move fee collection. They argued that communities needed to collect fees. If communities did not collect fees, how would they be able to cover day-to-day maintenance expenses?

Managed Decentralized Wastewater Treatment Systems in Indonesia": 71. 25 Ibid., 6, 11, 56. 

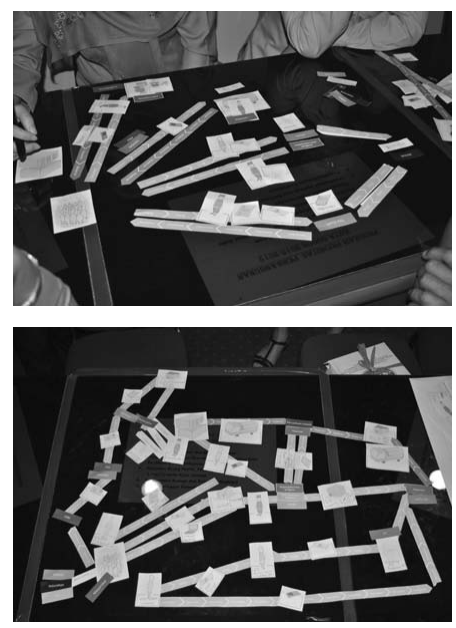

Figures $5 \mathrm{a}$ and $5 \mathrm{~b}$

Examples of mappings made using the Management Model game. Photos by Tanja Rosenqvist.
26 Service blueprint is a tool widely applied within the sub-field of service design to map customer service journeys, see e.g., G. L. Shostack, "Designing Services That Deliver," Harvard Business Review January (1984): 133-39.
In this situation I decided to take an activist approach and to insist that the groups move fee collection. I did so believing that shifting responsibility for fee collection away from communities was the key to accomplishing a new management model. If responsibility for fee collection was moved either to the local government (which already collected fees for centralized sanitation) or to the water utility (which already collected water tariffs), fees would definitely be collected, and funds would accumulate so that local government or the water utility could desludge, rehabilitate, and maintain the systems. If communities remained responsible for fee collection, I believed they would also implicitly remain fully responsible for operation and maintenance. I, in other words, believed that shifting responsibility for fee collection would be a means of shifting accountability relations as well.

After some debate, local government stakeholders agreed to (try to) move fee collection (but only on paper), and a second design game was introduced: the Management Model game. This game, inspired by Service Blueprints allowed participants to discuss in greater detail where and how responsibility for fee collection, desludging, and system rehabilitation could be moved and how it might work in practice. ${ }^{26}$ The game consisted of three types of game pieces:

- Pieces (small drawings) representing objects (e.g., money, construction materials, bills, documents, desludging trucks, phones, and computers);

- Pieces (colored arrows) representing the movement of money, materials, or communication between stakeholders; and

- Pieces (colored squares) representing relevant stakeholders, including CBOs, NGOs, various local government departments, and the water utility.

The groups were encouraged first to map how fee collection could take place (e.g., who could collect the fees, how, with which means, and where the money would go after collection). They were then asked to map the process of desludging and afterward the process of system rehabilitation. At the end of these three sequences, the three groups had created visualizations of possible co-management models. (See Figures 5a and 5b.)

All three groups successfully mapped co-management models so that responsibility for user fee collection, desludging, and rehabilitation were placed (at least partially) outside communities. Their solutions were pragmatic. Two groups suggested that communities already connected to the centralized, piped, water network might pay fees through their water bills, while other communities would have to remain responsible for fee collection. The third group suggested an NGO could get involved in fee collection. 
Although all three models were deemed feasible, local government participants recognized they would each call for regulatory changes, and the local government stakeholders were reluctant to initiate such changes. From their perspective, decentralized sanitation systems should be managed by communities.

\section{Shifting Toward Alternative Matters of Concern}

In the days following the workshop, $\mathrm{CBO}$ members were interviewed to explore their potential shifts in matters of concern. The interviews were transcribed and compared to previous interviews to identify shifts.

Although a redirected public had not emerged, indications of new matters of concern did emerge. For example, $\mathrm{CBO}$ members talked about co-management as a good option, although an option somewhat out of reach. For one CBO leader, the workshop had shown that local government might be able to play a larger role in decentralized sanitation service provision. As he explained,

the thing is, I previously didn't know it was possible.

During the workshop I saw that there are options that are

probable to implement... for bigger maintenance or for collecting user fees or other ideas that I think are good. It will be great if they can implement those ideas.

Another CBO leader, who also talked positively about co-management, was concerned about the feasibility. The workshop had made him aware of the potential barriers for realizing a co-management model:

I agree, if you see it that way, it is only logical that PDAM [water utility] is also responsible for treating the wastewater. But then it comes back to the bureaucracy. I hear that, even among the local government [staff] themselves, [they] have a problem reaching agreement. That is why I feel it is a sad thing that they cannot reach an agreement of something that is actually going in the right direction."

Although CBO members still were concerned about the lack of community "awareness," they now showed greater concern for the lack of local government involvement and for the ways in which regulation and bureaucracy seemed to be barriers for co-management.

\section{The Role of the Designer in Redirecting Publics}

As the design literature has clearly demonstrated, designers can play a role in making publics but also, as demonstrated above, in redirecting publics toward alternative matters of concern. On the basis of my experiences in redirecting publics through design, 
I, however, suggest that doing so calls for long-term engagements, activist proposals to prompt participation, and most importantly, comprehensive ethical considerations.

Redirecting publics is neither a quick task nor an easy one; it might involve dealing with societal norms and even fear. Through my four to six engagements with each $\mathrm{CBO}$ member over the course of a year, I did not successfully redirect the existing public; however, I did see signs of a new matter of concern emerging, which suggests that redirection might have been possible, given enough time and iterative attention. My experience further suggests that societal norms and values, as well as fear, create barriers for redirecting publics. Further research could therefore explore how to deal with such barriers as part of infrastructuring practices.

Redirecting publics furthermore calls for activist "proposals to prompt participation"-proposals that question not only existing matters of concern but also engrained societal norms and values. To illustrate, I used activist proposals to question the concern for a lack of community awareness and to propose an alternative matter of concern: the lack of ongoing support from local government. The Responsibility Game specifically, in a very visual manner, highlighted and questioned the number of responsibilities currently assigned to communities.

As an activist practice, redirecting publics should never occur without comprehensive attention to ethical considerations. DiSalvo has already noted how the construction of publics brings to mind visions of propaganda and misinformation. ${ }^{27}$ Redirecting publics through activist proposals seems even more ethically contentious, and the fear displayed by one of the CBO leaders seems to confirm this. Based on my experience, a few specific ethical considerations stand out: the importance of dealing with the potential discomfort of participants; the need for transparency about both process and goal; and the value of comprehensive research into existing matters of concern and historical legacies. These considerations are further explored below.

Participant discomfort. Designers engaged in redirecting publics must deal with any potential discomfort of participants. As described, one CBO leader felt particularly uncomfortable expressing his (negative) experiences. I tried to ease his fear by normalizing his experiences, suggesting that many communities had similar challenges, and by assuring him that the workshop would be a safe space in which he could share as much or as little as he felt comfortable. Importantly, I did not try to persuade him, but only provided information that allowed him and other $\mathrm{CBO}$ members to decide for themselves whether they were interested and comfortable participating. Being redirected toward an alternative matter of concern should always be a voluntary choice, for obvious ethical reasons. 
Transparency. Designers who engage in redirecting publics should ensure that both the process and the goal are transparent. For example, transparency might involve clearly expressing one's own matter of concern and ideas of how things might be "better." To illustrate, using the Responsibility Game, I explained that the main issue from my perspective was a lack of ongoing support from local government. I also made the goal of the co-design workshop clear by visually demonstrating the co-management model, which I intended to promote during the workshop. By being explicit about my matter of concern and goal, I allowed CBO members to "self-select" for the workshop and for the redirected public.

Comprehensive research. From an ethical perspective, designers involved in redirecting publics should conduct comprehensive research into existing matters of concern and understand why they were formed in the first place. In the "Governing Futures - Voices and Wastewater" project, I conducted more than 60 interviews in the case study city before redirecting the scattered public. The purpose of these interviews was to explore the day-to-day experiences of community members and their existing matters of concern, as well as to identify historical legacies and political economies that might influence these matters (e.g., gotong royong). ${ }^{28}$ This research allowed me to appreciate existing matters of concern and their origin and made questioning them and redirecting the public toward alternative matters of concern possible in an informed and ethical manner.

Given how ethically contentious redirecting publics can be, designers might question whether they should redirect publics at all. Is redirecting publics toward alternative matters of concern too activist, or too political? Is it ethical? Do designers really have the agency to decide what is in the best interest of the common good and what is not? Any answer to these questions of course is highly subjective and circumstantial. Should designers redirect publics toward seeing climate change as a hoax? The answer here is simple: of course not! Should designers redirect publics toward a more critical perspective on the types and quality of public services they receive? I believe the answer to this question is yes. In this posttruth era, in which publics are often formed around poor information, misinformation, or a lack of information (the need for the "fact-checker" in recent U.S. political debates bears witness to this reality), we could equally ask: Are designers who do not use design's emancipatory and collaborative tools to redirect publics behaving ethically? These questions warrant far more research, case studies, and discussion to further elaborate what redirecting publics through design means. For now, designers might take air." Local governments are therefore legally responsible for providing sanitation services, which provides a strong legal and ethical argument for promoting co-management. 
these ethical considerations seriously and acknowledge that what is in the best interest of the common good is a highly subjective and circumstantial matter. Nevertheless, as John Dewey noted, "No [hu]man and no mind was ever emancipated merely by being left alone." ${ }^{29}$

\section{Conclusion}

As many design projects have demonstrated, designers can play an important role in gathering publics around shared matters of concern. However, as demonstrated in this paper, the gathering does not guarantee that the public will act in its own best interest or in the best interest of the common good. A shared matter of concern might represent only one perspective on a far more complex issue. In such cases, designers might play an important role in questioning existing matters of concern so as to redirect publics toward alternative matters of concern.

Redirecting publics calls for infrastructuring practices that can deal with societal norms, values, and even fears, and for activist proposals to prompt participation. More importantly, it calls for comprehensively considering the ethical implications. In this paper I have argued that designers who engage in redirecting publics should be aware of and deal with any potential discomfort of participants, should share their own matters of concern explicitly to allow for an open and transparent process, and should conduct comprehensive research into existing matters of concern and their historical legacies. These actions allow members of a scattered public to freely decide whether they want to be redirected-or not.

\section{Acknowledgement}

The Australian Government Department of Foreign Affairs and Trade has funded this research through the Development Research Awards Scheme (ADRAS). The author thanks Katie Ross for sharing her deep insights into the works of John Dewey and the three anonymous reviewers for their invaluable critique. 